IMAGE IN CARDIOLOGY

\title{
Giant coronary aneurysm in Churg-Strauss syndrome
}

\author{
Marc Hartmann $^{1 *}$, MD, PhD; Elly M.C.J. Wajon ${ }^{1}$, MD; Gert K. van Houwelingen ${ }^{1}$, MD; Martin G. Stoel ${ }^{1}$, MD; \\ Clemens von Birgelen ${ }^{1,2}, \mathrm{MD}, \mathrm{PhD}$
}

1. Department of Cardiology, Thoraxcentrum Twente, Medisch Spectrum Twente, Enschede, The Netherlands; 2. MIRA - Institute for Biomedical Technology and Technical Medicine, University of Twente, Enschede, The Netherlands

This paper also includes accompanying supplementary data published at the following website: www.eurointervention.org

A 64-year-old male with Churg-Strauss syndrome (CSS) presented with worsening dyspnoea without chest pain besides having long-standing asthma. There were no cardiovascular risk factors. The electrocardiogram showed signs of prior anterior infarction. Echocardiography demonstrated severely depressed left ventricular function (ejection fraction 30\%). Multislice cardiac computed tomography revealed a giant coronary aneurysm
(Figure 1A and Figure 1B) of the left circumflex coronary (LCX) artery of $4 \mathrm{~cm}$ diameter with mural thrombi (Figure 1B) and also aneurysmatic changes of the right coronary artery (RCA) with proximal occlusion (Figure $1 \mathrm{~A}$ ). Coronary angiography showed aneurysmatic changes of the LCX with collateral filling of distal RCA and mid-segment occlusion of the left anterior descending (LAD) (online Figure 1C and 1D, Moving image 1- Moving image 3).
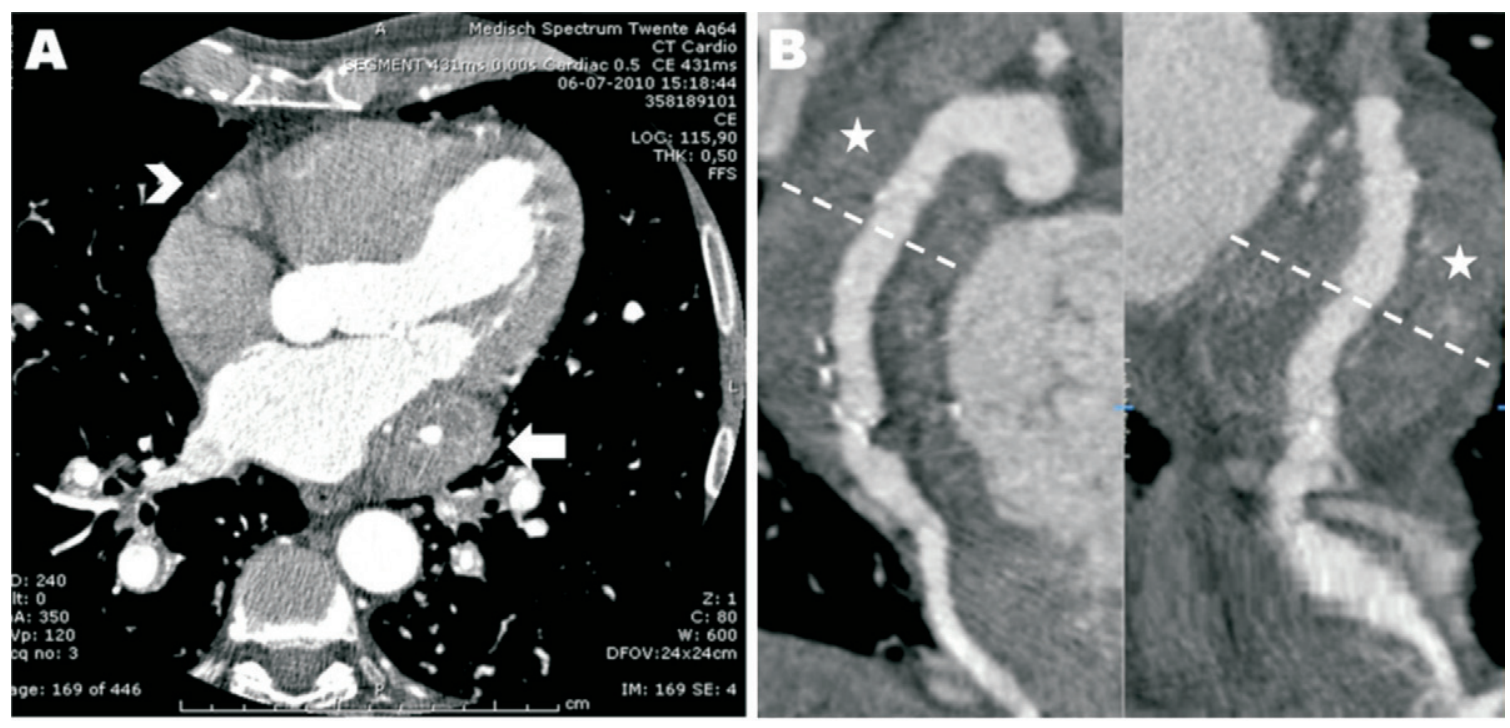

Figure 1. Multislice cardiac computed tomography imaging $(A, B)$ showed a giant coronary aneurysm of the LCX artery (arrow in A) with a diameter of $4 \mathrm{~cm}$ and mural thrombi (asterisk in B) and aneurysmatic changes of the RCA with proximal occlusion (arrowhead in A).

\footnotetext{
*Corresponding author: Department of Cardiology, Thoraxcentrum Twente, Medisch Spectrum Twente, Haaksbergerstraat 55 , 7513 ER Enschede, The Netherlands.E-mail:m.hartmann@mst.nl
} 
Single-photon emission tomography confirmed an ischaemic cardiomyopathy with irreversible defects. Treatment was carried out medically, and an internal cardioverter-defibrillator was implanted.

Coronary aneurysms are uncommon; they are usually due to atherosclerotic disease and only in a minority of cases are they the result of an autoimmune vasculitis ${ }^{1}$. CSS is a rare small-vessel vasculitis with asthma and eosinophilia ${ }^{2,3}$. There are only a few reports with CSS and involvement of major coronary vessels with aneurysmatic changes $^{1-3}$. The toxic effects of eosinophils on the coronary wall may result in aneurysmatic enlargement ${ }^{1-3}$. This case describes extensive coronary involvement leading to an ischaemic cardiomyopathy, probably due to thrombotic occlusions and distal coronary embolisations ${ }^{1}$.

\section{Conflict of interest statement}

The authors have no conflict of interest to declare.

\section{References}

1. Syed M, Lesch M. Coronary artery aneurysm: a review. Prog Cardiovasc Dis. 1997;40:77-84.
2. Drogue M, Vergnon JM, Wintzer B, Antoine JC, Malquarti V. Prinzmetal's angina pectoris revealing aneurysma of the right coronary artery during evolution of Churg-Strauss syndrome. Chest. 1993;103:978.

3. Hellemans S, Dens J, Knockaert D. Coronary involvement in the Churg-Strauss syndrome. Heart. 1997;77:576-8.

4. Riksen NP, Gehlmann H, Brouwer AE, van Deuren M. Complete remission of coronary vasculitis in Churg-Strauss syndrome by prednisone and cyclophosphamide. Clin Rheumatol. 2010 Mar 28. [Epub ahead of print]

\section{Online data supplement}

Figure $1 \mathrm{C}$ and Figure $1 \mathrm{D}$. Coronary angiography (with CLS guiding catheter) also showed extensive aneurysmatic changes of the LCX artery (arrow in C, D) with collateral filling of distal RCA which is proximally occluded (arrowhead in C, D). The LAD showed mid-segment occlusion with minor collateral filling of the distal part (asterisk in C, D).

Moving image 1. Coronary angiogram RCA.

Moving image 2. Coronary angiogram LCA\#1.

Moving image 3. Coronary angiogram LCA\#2. 